\title{
Interactive simulations for promoting transdisciplinary understanding: a case study of the Western Cape fisheries, South Africa
}

\author{
CN GERWEL PROCHES AND S BODHANYA
}

\begin{abstract}
Simulations have proven beneficial in enabling participants from various backgrounds to meaningfully engage in learning from experience. The aim of this paper is to investigate how interactive simulations can play a role in navigating the changes faced in a multistakeholder setting, characterised by users dependent on marine resources and an authorising institution. Relevant literature in the areas of simulation and gaming, change management, systems thinking, and complexity theory was examined. A qualitative research approach and purposive sampling were employed. Interviews were first conducted with diverse stakeholders in the Western Cape fisheries of South Africa to determine the issues. A simulation was thereafter designed. The main findings from this study indicate that simulation use illustrates how the various stakeholders in a system interact, and how their actions and decisions influence each other. The simulation may be used in other areas of natural resource management, as well as in other kinds of multistakeholder scenarios.
\end{abstract}

Keywords: Simulation and gaming, Change management, Fisheries, Multi-stakeholder scenarios, Systems thinking, Complexity theory

Disciplines: Conflict Resolution, Leadership Studies, Management Studies, Natural Resource Management

\section{Introduction}

The Western Cape fisheries of South Africa is challenged by immense complexity and change arising from the interactions which occur between the multiple stakeholders. The aim of this paper is thus to investigate how interactive simulations can assist in navigating the changes confronting the fishing industry.

Thiagarajan (2003, pp. 235) presents a useful definition of a simulation as "the representation of the objects, characteristics, behaviours, and relationships of one system through the use of another system", which contains play objects, goals, rules, and roles. Simulations are a useful way for people to stand outside a system but yet gain a holistic perspective. Klabbers (1989) indicates the use of simulations in effectively dealing with complex issues and situations involving many stakeholders with their own unique viewpoints. Simulations allow for double-

${ }^{1}$. Cecile N. Gerwel Proches and Shamim Bodhanya are attached to the Graduate School of Business and Leadership, University of KwaZulu-Natal, Durban, 4000, South Africa. Contact details: gerwel@ukzn.ac.za; and bodhanyas1@ukzn.ac.za. Acknowledgements: This paper is based on sections of work from the MCom dissertation of Cecile Gerwel. All those who participated in the study are thanked for their involvement. Serban Proches and Yvonne Gerwel are acknowledged for assistance with fieldwork. The anonymous reviewers are thanked for useful feedback. 
loop learning, which refers to a fundamental change in underlying behaviours, due to the various roles, rules and behaviour that participants display. Simulations are powerful in that they unearth how people naturally deal with problems and relate to others in the real world.

Simulations must be based on a sound, methodologically and empirically tested conceptual model, and relevant literature must be consulted (Chua, 2005). Leigh (2004) advises that the problem be identified and that its causes and characteristics be determined. It is important that the designer acquire input both from former studies and from real world participants. Simulations cannot however incorporate all issues. Critical elements need to be simplified and effectively represented (Leigh, 2004). It is important to not get completely caught up around realism but the focus should instead be on verisimilitude (Borodzicz, 2004). Verisimilitude refers to the activities in the simulation being similar to those in the real world, with the aim of having participants carry over experiential lessons to the real world (Lane, 1995).

Borodzicz (2004) argues that it is critical that simulations have outward simplicity, yet inner complexity, but also warns that complex games may fail, and encourages the use of simple, yet powerful games where participants better understand issues by focusing on the achievement of a few goals. Simulations consist of three set sequences: briefing, the action and debriefing, as well as further interrelated elements composed of rules which govern actions, specific roles and the relevant situations, and any physical records (Leigh, 2004). The debriefing phase is the final stage in the simulation which provides participants with an opportunity to make connections between learning and the game.

This paper is structured as follows. A brief description of the contextual background follows, and the methodology is thereafter outlined. The results which focus on findings from the interviews, and the consequent design of the simulation, and the findings thereof are then presented. Reflections on the use of the simulation and recommendations are highlighted, followed by the conclusion.

\subsection{Contextual background}

The context of the study was the Western Cape fisheries of South Africa. There are multiple users in this industry, comprising small-scale fishers, commercial and recreational fishers. However, this range and intensity of stakeholder activity is taking place within a limited supply of marine resources. An authorising institution is tasked with the conservation, management and sustainable use of the marine resources. The Western Cape fisheries have been affected by various changes, most notably, government policies that have resulted in adjustments to the allocations of the various groups. In addition, there has been conflict between the various stakeholders, specifically around the demand and supply of the marine resources, and in response to the multitude of changes that have affected the system. The industry has been significantly impacted by amongst others, the apartheid past of South Africa, government policies such as the Reconstruction and Development Programme (RDP) and Growth, Employment and Redistribution Programme (GEAR), and the introduction of the Marine Living Resources Act (MLRA) (No. 18, 1998). 


\section{Methodology}

A qualitative research approach was employed. Fifteen interviews were conducted between July-August 2009 with the various stakeholders in the Western Cape fisheries to enable an understanding into the critical issues within the fisheries industry, and to consequently construct a simulation, which was essentially a simplified model of the real world.

The simulation was first piloted with students at the University of KwaZulu-Natal in Durban in September 2009, and adjustments were consequently made. The simulation was thereafter conducted with fishers on the West Coast, and finally with the authorising institution at their offices in Cape Town in October 2009. Participants had roles in the interactive simulation, as the emphasis was on collective learning. There was a strong focus on communication and interaction between those involved.

The simulation commenced with an initial briefing to prepare participants. There were rules or protocols regarding what was acceptable and what not, as well as materials or equipment that were used. Each player had specific roles, and there were also boundaries, certain goals and objectives, props and other pertinent information (for example documents and memos). The simulation involved three rounds, signifying time periods. The simulation concluded with a debriefing session to reflect on lessons that were learnt, and specifically linked lessons from the simulation to the real world fisheries system. This critical phase allowed for evaluation of the simulation and for ways of thinking about improving the fisheries system. The conclusion of the simulation runs signified the end of the fieldwork component of the study.

\section{Results}

The key findings based on the analysis of the interviews are first presented. This will be followed by a description of how the simulation was designed, and the key elements that form part thereof. Descriptions of the trial and actual runs of the simulation will be provided, and the findings which are based on data analysis will be presented thereafter. Figure 1 illustrates the approach undertaken in the study.

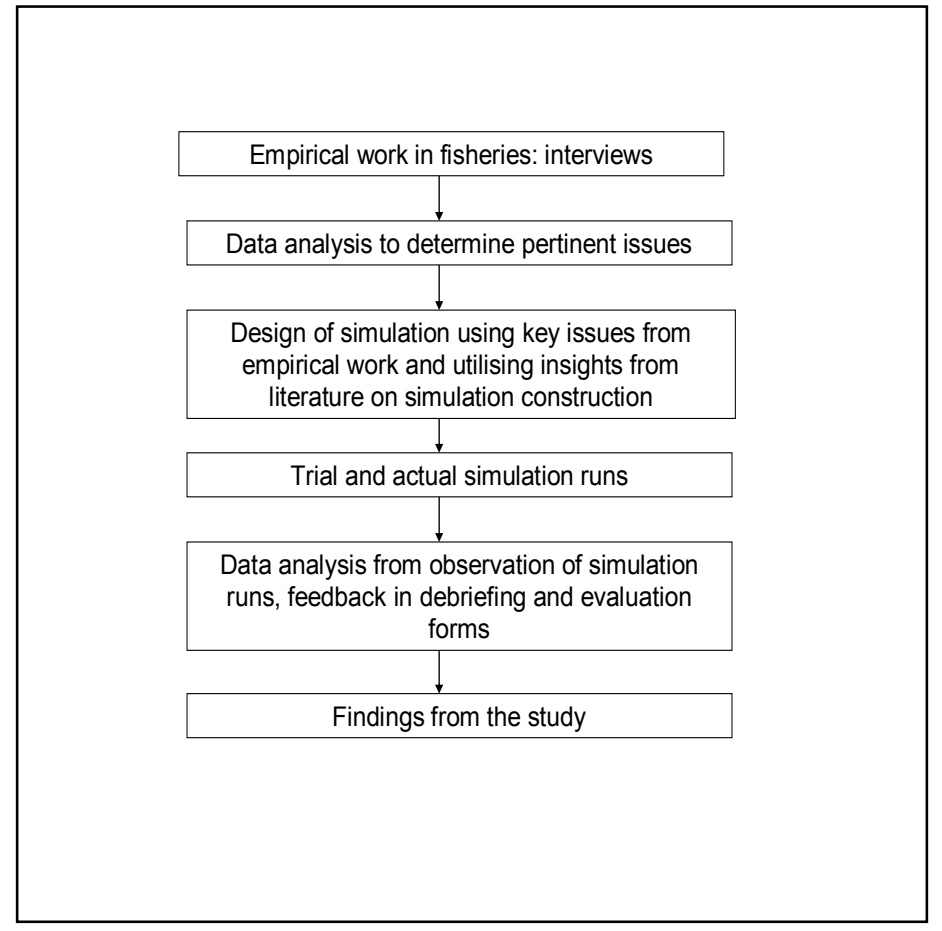

Figure 1: Flow diagram of approach undertaken in study 


\subsection{Findings from the interviews}

The results of the interviews were carefully studied in order to decide how to structure the simulation. As it was not possible to focus on all the issues in the simulation, attention was directed at the major issues considered to be of importance. The issues that were selected were also deemed to be feasible to replicate, considering the constraints of designing an interactive simulation given the available time and resources. The main issues that were selected are listed below.

\subsubsection{Decision-making in a multi-stakeholder context}

There was a complex situation involving multiple stakeholders, comprising the government, authorising institution, commercial, recreational and small-scale sectors. The contention was mainly about the demand for a limited supply of marine resources. Respondents had a tendency to highlight the differences and faults between the respective stakeholder groups.

\subsubsection{Equity}

The role of government and the authorising institution was an important issue that came to the fore. The ability to allocate resources fairly, while balancing the needs of all stakeholders was crucial. Stakeholders had the inclination to consider how they were treated by other stakeholders and by the authorising institution, as well as how other stakeholders were treated by the authorising institution. A contributing factor to the many problems was the perception that there were some stakeholders that had easier access to the marine resources than others. The perception that government was seen to be taking away allocations from certain stakeholders to give to others, thus leaving some adversely affected was of concern to many respondents. The pressure on government from the various stakeholders was thus noted. It is necessary, as highlighted by Wilson (2006) to view and treat the world's oceans as a complex adaptive system and consequently deal with human activity differently.

Government decision-making and protocol, as well as the need for government to take accountability for decisions that were made, were deemed critical. Concerns around authority, timeous decision-making, staff changes and the fact that everything began and ended with government were highlighted. There was a strong desire for government to work with and be accessible to everyone, including those on the ground. Townsley (2010) found it critical to adopt a people-centered approach in marine policy formation. Glavovic and Boonzaier (2007) highlighted the need for enhanced state capacity and increased partnerships between government and civil society.

\subsubsection{Monopoly of powerful interests}

The assignment of rights to the commercial sector, particularly on the basis of job creation, was a particularly controversial issue that came to the fore. There was much dissatisfaction with job losses as a result of the closure of factories. There was a sense amongst some that the commercial companies should have taken more responsibility, and that government should have intervened.

\subsubsection{Sustainable livelihoods}

The dependency of the small-scale fishing communities on the marine resources for their livelihoods featured strongly, as well as the lack of alternative employment. Townsley (2010) 
notes the importance of reducing dependency on marine resources as a way of preserving such ecosystems. The added complication of job loss and being unable to earn an income due to a lack of abilities was highlighted. The need for education and training programmes was mentioned by Glavovic and Bonzaier (2007) as a means of addressing coastal poverty. Feelings of frustration at not being able to take care of families, non-recognition and powerlessness, and loss of human dignity were described, as well as the inability to obtain credit and equipment, and being dependent on others. The use of protest actions and media were cited as some of the measures taken to resolve the problems. The media in particular came through strongly as an advantage for some but not for others. The involvement of nongovernmental organisations was deemed critical.

\subsubsection{Platform for constructive dialogue}

Proper communication between all stakeholders and participation by all in decision-making during change was regarded as critical. Responsible leadership, coupled with the importance of reporting back to people on the ground and having accountability, as well as the management and distribution of resources and finances were considered essential.

\subsection{Simulation design}

The issues that emanated from the interviews were accordingly examined along with the change management and simulation literature, to find ways to effectively represent and simplify them. Further information regarding the findings pertaining to the fisheries is available in Gerwel (2009) and the final version of the simulation is presented in Gerwel and Bodhanya (2012).

The real world stakeholders of the fisheries were not included in directly making contributions to the design of the simulation. This was mainly due to the belief that a thorough understanding of the context had been gained from the interviews, observations and secondary data, as well as time constraints.

\subsubsection{Scenario}

It was critical that the simulation not make any direct reference to fisheries, so that any conflict between the various stakeholders be avoided. Potential ideas for the scenario included sustainable agriculture, water, dams, wetlands and invasive species. It was finally decided that the simulation would focus on the construction of simulated rabbit cages, which are essentially cardboard boxes. This was distant enough to avoid any negativity but still close enough to have participants relate to the complexity. The simulation was also considered appropriate for use with a diverse audience.

\subsubsection{Purpose and learning objectives}

The simulation was designed to immerse the learners in a multi-stakeholder scenario aimed at allowing participants to gain an understanding into the various stakeholder perspectives. Participants thus had to have an opportunity to reflect on their current mental models (Senge, 1994). The simulation furthermore had to portray shared mental models so that participants could view the whole, and see the different viewpoints. It was critical to challenge common misperceptions that participants may have initially arrived with. 
The simulation objectives were to provide an experience where participants could see how their interactions and decisions unfolded, sometimes at alarming rates, and how changes infiltrated into other areas (Bamford \& Forrester, 2003). It was critical for the participants to experience that they were all part of a larger system, and that they see how their decisions and actions, and likewise those of others, impact the system (Montouri, 2000; Styhre, 2002). Participants had to experience how unintended consequences arise. The simulation also had to result in participants questioning their usual way of doing things. They had to realise their contribution towards the problems and take accountability for their actions (Senge, 1994). It was necessary to incorporate failure, to intensify the learning experiences, and to engage all in a better understanding of leadership (Grint, 2007).

Learning from practical experience was thus of the utmost importance to allow all participants to develop the collective ability to perform more effectively (Hayes, 2002). Double-loop learning was however desired so that participants would challenge their current thinking and basic beliefs and assumptions, particularly in complex situations.

Participants had to comprehend how attitudes toward communication and participation shaped matters. Participants had to see the importance of involving all stakeholders from the pre-implementation stage, and also how critical it was to acknowledge the emotions of all (Van Tonder, 2004). This was also so that participants could see that those in charge did not have all the answers, but that it may have been better to have everybody work together towards shaping the future (Ferdig, 2007).

As important was the need for participants to understand how to respond to ambiguity and unanticipated events and in so doing, become adaptable. They also had to grasp the limits of conveying and delegating plans, and learn to expect the unexpected (Callan, Latemore \& Paulsen, 2004). Moreover, they had to realise the importance of not holding on to the past and using things that worked back then. The simulation was therefore centred on getting participants to work with difficulties, engage in collective sense-making, collaboration and interpretation, and look for opportunities for growth (Ashmos, Duchon \& McDaniel, 2000). Related to this was the necessity of having participants gain change management skills.

\subsubsection{Roles}

The simulation portrayed three major groups, based on the real world context. This was therefore a multi-stakeholder scenario aimed at allowing the participants to comprehend each other's perspectives and mental models. There was a government group, based on the government and authorising institution as is in reality. There was a company which comprised of executives and workers, responsible for the production of the simulated cages. The groups in the simulation would essentially represent different stakeholder groups with conflicting interests. There were roles for media and civil rights representatives.

\subsubsection{The problem}

Participants had to work through a complex problem involving various interconnected processes, so that they would gain a holistic view of the problem presented by multiple stakeholders. The task was to have workers produce simulated rabbit cages using various materials, including cardboard paper and scissors, under the guidance of the executives, with government overseeing the project. It was important that the activities be challenging enough for all to stay focused, yet not too overpowering for some. The simulation was also constructed to deal with the various issues but in a manner that allowed participants to 
choose what to investigate, how choices would be made, and who would be included. Furthermore, the problem was seen to be a way of facilitating joint dialogue and a community of learning. The simulation attempted to portray elements of realism and user-friendliness, but more importantly verisimilitude, to ensure that lessons learnt from the simulation could be transferred to the real world (Lane, 1995).

\subsubsection{Limited information and time}

Participants had to be overwhelmed by a tremendous amount of ambiguity and uncertainty, but also an array of demands which had to be fulfilled in a limited time. The simulation was thus structured around three stages, the first of which was deliberately limited in time, so that participants could experience the pressure. Stages were considered appropriate rather than 10 rounds for example, as the plan was to have minimal disturbance to allow the participants to engage in the flow of the simulation. The stages specifically would create pressure for participants to make choices whether to cooperate or compete with others.

It was considered appropriate to have participants experience consequences of their decisions in minimal time, through the stages. Decisions that were made in the first stage could for example result in outcomes fairly quickly. It was important to have the outcomes of ordinarily slow processes in reality accelerated and vice versa, such as the result of dismissing workers. Participants could therefore see how decisions and actions unfold at alarming rates, and would in the process experience unintended consequences. This was also a way of facilitating double-loop learning, and for people to take accountability.

Another important consideration in selecting the time structure of the simulation was to ensure that participants would be under such pressure that they would almost forget they were in a simulation, and would in the process bring out their true personalities.

\subsubsection{Resources and information}

The various groups had to commence the activities with unequal resources and information. The workers in particular had to experience what it was like to be dependent on others. The allocation of the resources was also planned to encourage communication and participation between the participants. The results of the choices that they made could then be illustrated in the simulation. The limited information and uncertainty could then assist participants in becoming adaptable and to expect the unexpected.

It was also decided to have the various groups in different rooms to further allow them to comprehend things on their own. The intention was to leave the workers deliberately ignored, so that they could experience feelings of powerlessness and having to wait on those who had the information and resources.

The aim was to initially empower the executives and government by having them be in charge of the resources, power and information. As the simulation proceeds, it however becomes clear that the leaders do not necessarily have all the answers and that they are also faced with uncertainty.

\subsubsection{Pertinent information and rules}

The briefing document spelt out information but was however not intended to provide participants with too much. The rules of the simulation were constructed to indicate acceptable behaviour and boundaries. 


\subsubsection{Unanticipated events}

A number of unanticipated events were added, mainly to keep the simulation lively but also to have respondents become more adaptable and open to learning (Borodzicz, 2004). The simulation was planned to have participants think that there would be three stages; there would however only be two. The second stage therefore incorporated the unanticipated events, and was primarily aimed at introducing pressure but to also allow participants to adapt to an ever-changing environment.

\subsubsection{Debriefing}

It was critical to draw out strong emotions that participants may have experienced in the simulation and to discuss key learning lessons that could be used for the real world. It was also considered appropriate to address the learning objectives during the debriefing phase. The debriefing was essentially focused on the decisions that participants made, specifically regarding communication, participation, strategy, and how they responded to the complexities.

\subsection{Findings from the simulation run}

The simulation was first piloted with post-graduate students at the University of KwaZuluNatal in Durban. Invitations were sent out to students from various disciplines to participate in the simulation. The suggestions for improvement by the participants were carefully studied to improve the simulation. Certain aspects of the simulation were thus changed after the trial run.

\subsubsection{Simulation run with the fishing community}

The simulation was run in a fishing town on the West Coast of South Africa. Approximately 25 people, 22 of whom were fishermen and a few community leaders attended. Figure 2 provides an idea of the interaction and illustrates the "rabbit cages", which are in essence cardboard boxes.

The simulation started about 15 minutes late, and was conducted in Afrikaans to accommodate the participants. It was challenging to deal with the participants' initial confusion. The participants became comfortable fairly quickly but the observation role was challenging due to the multi-faceted nature of the simulation.

The debriefing went well and it was satisfactory to hear the participants relate their experiences. Some participants did not share and not all aspects of the real world could be discussed. An attempt was made at bringing in the roles of the commercial and recreational sectors and the authorising institution, but the majority of the fishers were unable to relate. The leaders understood and made comments, but also explained that the fishers were not that involved in those aspects.

The group was compliant, yet extremely practical. Perhaps this had to do with the nature of their work. They were for example in the simulation, extremely quick with the production and really seemed to be immersed in the simulation. The evaluation forms were perceived to be challenging. Three of the fishermen could not read or write, and therefore required assistance. Others completed the forms but not thoroughly. This had to do with the fact that 
many of them did not complete their schooling. The leaders however seemed to do quite well with the forms, probably due to the training that they had received and also as a result of their knowledge.

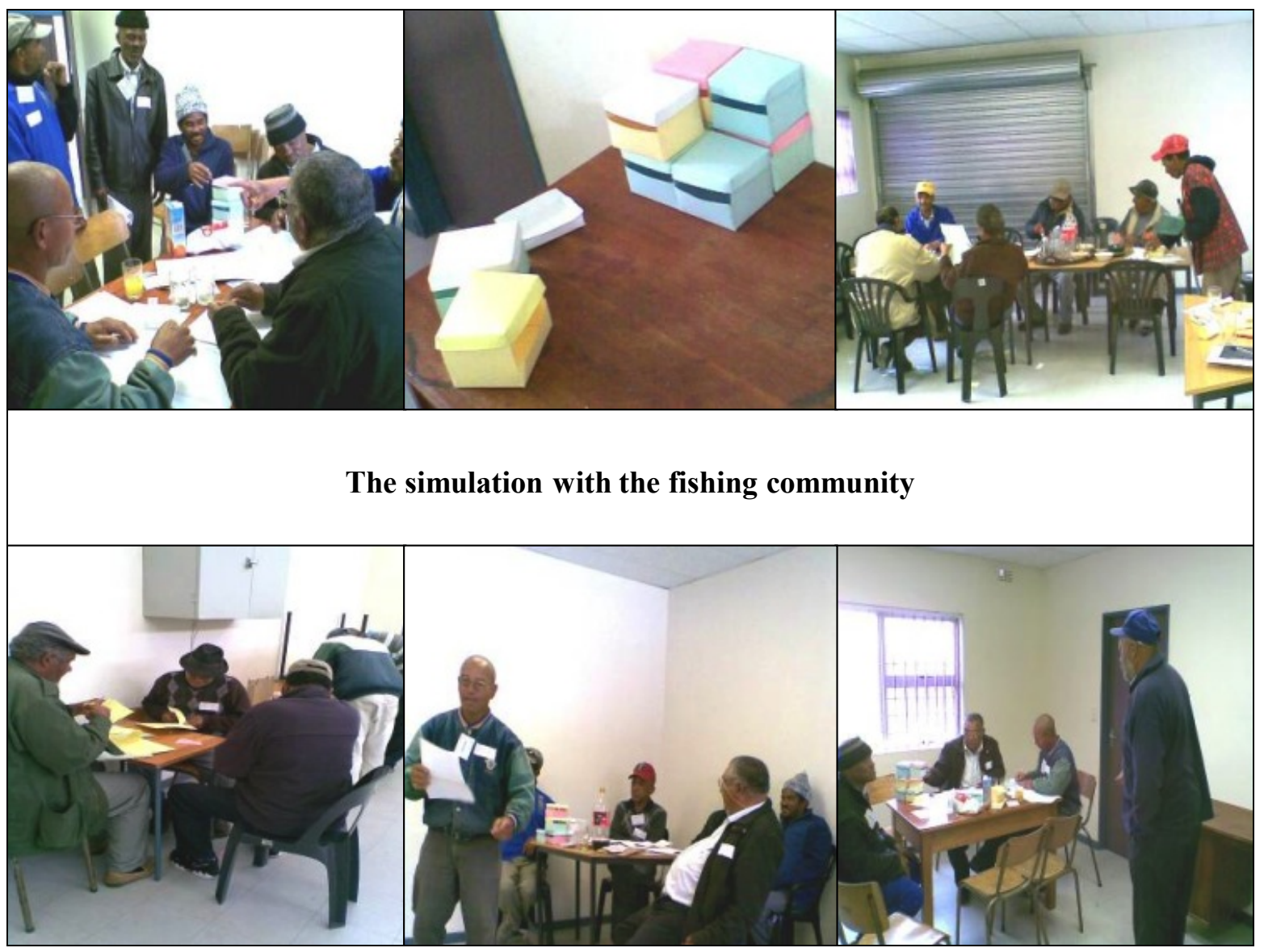

Figure 2: The simulation with the fishing community

Feedback from the leaders regarding their experience of the simulation indicated that they saw hidden talent in the fishers. They also added that they would like to use role-play exercises in future with the fishers. Mention was also made that something new had happened in that all the fishers had come together. The simulation may have been an important boost of confidence for the fishermen and may also have demonstrated to them that they have underutilised capabilities. The emphasis on communication and participation was particularly important.

\subsubsection{Simulation run with the authorising institution}

This simulation was run in Cape Town. The invitation was sent out to many people but only 10 arrived. The participants comprised mostly of young, junior scientific staff.

The simulation started late. The participants also appeared quite overwhelmed initially by the documentation. The participants assigned to the decision-making roles were fairly softspoken but managed in the end. After the assignment to the groups, one of the participants in the government role remarked how 'this government thing is quite good'. The same person however later was exasperated and cited miscommunication as a huge problem. 


\subsubsection{Reflections on the use of the simulation}

It took courage to face the blank stares during the briefing phase of the simulation. It was also a challenge to avoid divulging too much in order to cope with the participants' uncertainties. It would have been better had there been more participants and especially more of the stakeholders together. This would not only have facilitated interaction but would also have been a true test as to the success of the simulation.

A way to deal with the initial fears when looking at the blank faces was to remember that there was order in disorder (Leigh, 2004). Things fell into place, and no one simulation was identical to another because the people were different. The role of the facilitator changed as well. It was a journey of sense-making for both facilitator and participant alike. This was illustrated by the many people, who expressed how nervous they were in the beginning, but that things made sense later and that they soon fell into role. It is thus critical that the facilitator be prepared, yet flexible (Le Roux \& Steyn, 2007; Leigh, 2004).

It was difficult dealing with low numbers; this necessitates more intervention from the facilitator, which could affect emergence. Another challenge was waiting for people to arrive, and consequently not have enough time for the simulation, and the debriefing phase. Preparation, adaptability and quick thinking from a facilitator are critical.

The debriefing phase is critical and is really the chance to make a difference, but it does vary tremendously depending on the audience. This was illustrated by the fact that not all of the participants could understand what was happening in other areas, and also that some participants, e.g. the community leaders had more exposure to the different areas, whereas the fishers mostly had to do with fishing.

It was rewarding and a relief when people started to make connections during the debriefing phase. The facilitator must have enough practice to become skilled at facilitating this phase, and must be flexible and know when to make judgment calls. Long after the simulation was over, questions still arose about how the debriefing went and what else could have been added.

It was reassuring to see a fairly academnically and intellectually orientated group with hardoy any education, work through the simulation. This means that the simulation may have had the desired outward simplicity, yet inner complexity, considered critical by Borodozicz (2004). The simulation also became more user-friendly after incorporations from the trial run, and this was demonstrated by the fact that no-one mentioned experiencing any difficulties in such regard. This was particularly the case with the briefing phase, which Leigh (2004) points out is critical to captivating the interest of participants.

The simulation was a start to dealing with the complex issues involving the many stakeholders in the fisheries system in the Western Cape. The phases in the simulation were critical in illustrating the consequences of decisions made in minimal time (Jackson, 2004). The emergence of a union in the one simulation, as a result of not communicating with workers is an example.

A potential weakness could be that of researcher bias, where certain issues were selected for inclusion in the simulation design. The simplification and representation of the issues from the interviews was more challenging than portrayed by most literature. It is critical to not have exact duplication, as was found by Feinstein, Mann and Corsun (2002) but the reality is that there was a tendency to be quite literal in the conceptualisation of the simulation. 
Another challenge was to have activities that were engaging for all participants, considering their diverse backgrounds.

An attempt was made for the participants to view the whole system. This unfortunately was not realised fully due to the background of the participants, as well as the roles that participants had in the simulation. Only certain participants therefore had an opportunity to view the whole system, and this is in contradiction to many studies (Le Roux \& Steyn, 2007; Geurts, Duke \& Vermeulen, 2007). Some participants could therefore not take action as they were not enabled to do so in the real world.

Participants had a chance to participate in an interactive environment whereby they engaged with ideas and principles, as highlighted by Jackson (2004). The use of various roles may have facilitated double-loop learning for the participants, and this was further induced by having participants experience the consequences of their actions. The simulations may have been a beginning in facilitating a move towards continuous learning and improvement. There is, however, no way of knowing whether this was definitely the case and could not be assessed within the confines of this study. The simulation did however highlight to participants the importance of not being overly-dependent on plans.

The concept of problem-solving within simulations was interesting to note. Although the simulation made no direct reference to the fisheries system, participants did seem to draw key learning lessons for their contexts. It cannot be stated with certainty however that they discovered new features to the problem or generated new ideas, as found by Geurts et al. (2007). Most participants in the system may have been aware of their problems, but not on a deeper level. The simulation allowed participants to further develop critical skills, such as communication and decision-making, and provided an opportunity for critical reflection, as found by other authors (Le Roux \& Steyn, 2007).

The results of the involvement of both the leaders and fishers in the simulation can be correlated to findings from a few studies. Firstly, the simulation permitted for involvement from participants from different levels. This led to key learning lessons for the leaders as to how to involve the fishers in future. The simulation was successful in bringing the fishers together, and was a step towards strengthening ties. It also allowed the fishers to see their part in the big picture (Geurts et al., 2007).

The facilitation of a simulation, and the qualities of the facilitator were undoubtedly critical to the success of the simulation, as found by other authors (Keys \& Wolfe, 1990; Borodzicz, 2004; Leigh, 2004). It was critical to have adequate knowledge of the workings of the simulation, but also to strike a good balance between being prepared, yet flexible. What was also required was a thorough knowledge of the context, so as to be able to relate to participants during the debriefing phase.

Most participants highlighted that the simulation made them think differently about the real world, whereas a few indicated that the simulation had not made them think differently because the simulation showed how the real world was. The question then is whether those who found the activities in the simulation similar to the real world took away any learning to the real world. Thus, findings from this study cannot fully support claims by other studies around verisimilitude (Borodzicz, 2004; Keys \& Wolfe, 1990; Lane, 1995).

The study was significant in demonstrating that simulation use can assist stakeholders to gain better insight into critical issues around participation and communication in the Western Cape fisheries. The involvement of people from different levels in the simulation 
strengthened ties, and people could thus see their part in the bigger picture. The importance of being adaptable and possessing the necessary capabilities, rather than being overly-reliant on plans, was illustrated to participants through the various occurrences in the simulations. Furthermore, the simulation drew attention to the interactions between the various parts in the system and how unintended consequences occur.

\subsubsection{Recommendations}

The use of simulations for various disciplines, specifically in management, is highlighted in many studies, and is a useful way for conducting research. More academics and researchers can thus do research using simulations to not only teach students critical concepts, but it can also involve people from actual organisational settings, who may in turn benefit.

Simulation literature often does not highlight the difficulties of attracting people to a simulation. Research must be done into looking at how to facilitate this, and studies can also compare how people felt before and after the simulations. In a similar vein, the long-term effects of a simulation need to be assessed. There is no doubt that simulations are powerful learning tools, but they may be more effective in the beginning as a way to unleash learning opportunities.

Designing a simulation for a specific setting is challenging and current research does not adequately highlight this. Furthermore, designing a tailor-made simulation for a multiple stakeholder setting is a demanding task. Multiple considerations include being fair and ensuring that the simulation does not favour or negatively portray any stakeholder group, and finding activities to hold the interests of all. These areas around simulation design need further exploration. Despite the knowledge that the simulation must have adequate goals and challenge level, more work needs to be done around incorporating activities applicable to all.

The use of interactive simulations also holds much promise. This is an approach that works with people who are on different levels, some of whom may be technology-averse, which is often the case in a developing country. Practical areas of running simulations deserve more attention in the literature. These include highlighting the journey from stress to enlightenment, which the facilitator and participants experience. The influence of factors such as low numbers, late starts, disruptions, language, and group dynamics must be further investigated as to how they impact on the flow of the simulation. More studies must highlight the multiple abilities required from facilitators.

\section{Conclusion}

Based on the overall results, it can be asserted that the study highlighted the potential contribution that simulation use can play in assisting stakeholders in a natural resources management setting characterised by complexity due to multiple-stakeholder interactions. The research thus contributed to research collaboration between the natural and social sciences. The innate complexity within the specific real world setting was utilised, and the unique needs of learners were taken into account. The role of stakeholder demands, interactions, and perspectives in change were effectively illustrated. A variety of complex issues involving multiple-stakeholders were thus addressed. The simulation provided valuable input into a variety of issues around change, rather than in one area only. This allowed for a fairly accurate portrayal of reality. Other issues around the role of leadership, protocol, 
procedures, limited resources and information, uncertainty and lack of information, all of which characterise change processes, were also effectively highlighted in the simulation.

\section{References}

Ashmos, D.P., Duchon, D. and McDaniel, R.R. 2000. Organizational responses to complexity: the effect on organizational performance. Journal of Organizational Change Management, 13 (6), p. 577-594.

Bamford, D.R. and Forrester, P.L. 2003. Managing planned and emergent change within an operations management environment. International Journal of Operations E Production Management, 23 (5), p. 546-564.

Borodzicz, E.P. 2004. The missing ingredient is the value of flexibility. Simulation $\mathcal{E}^{\circ}$ Gaming, 35 (3), p. 414-426.

Callan, V.J., Latemore, G. and Paulsen, N. 2004. The best-laid plans: Uncertainty, complexity and large-scale organisational change. Mt Eliza Business Review, 7 (1), p. 10-17.

Chua, A.Y.K. 2005. The design and implementation of a simulation game for teaching knowledge management. Journal of the American Society for Information Science and Technology, 56 (11), p. 1207-1216.

Feinstein, A.H., Mann, S. and Corsun, D.L. 2002. Charting the experiential territory. Journal of Management Development, 21 (10), p. 732-744.

Ferdig, M.A. 2007. Sustainability leadership: Co-creating a sustainable future. Journal of Change Management, 7 (1), p. 25-35.

Gerwel, C. 2009. Exploring the use of simulation as a tool of change management. MCom Dissertation. Faculty of Management Studies, UKZN.

Gerwel, C. \& Bodhanya, S. 2012. Rabbit-Venture. Simulation \& Gaming, [online]. Available at http://sag.sagepub.com/content/early/2012/02/28/1046878111436168.full.pdf [Accessed 2 May 2012].

Geurts, J.L.A., Duke, R.D. and Vermeulen, P.A.M. 2007. Policy gaming for strategy and change. Long Range Planning, 40 (6), p. 535-558.

Glavovic, B.C. and Boonzaier, S. 2007. Confronting coastal poverty: Building sustainable coastal livelihoods in South Africa. Ocean E Coastal Management, 50, p. 1-23.

Grint, K. 2007. Learning to lead: Can Aristotle help us to find the road to wisdom? Leadership, 3 (2), p. 231-246.

Hayes, J. 2002. The theory and practice of change management. New York: Palgrave.

Jackson, M. 2004. Making visible: using simulation and game environments across disciplines. On the Horizon, 12 (1), p. 22-25.

Keys, B. and Wolfe, J. 1990. The role of management games and simulations in education and research. Journal of Management, 16 (2), p. 307-336. 
Klabbers, J.H.G. 1989. On the improvement of competence. In: J.H.G. Klabbers, W.J. Scheper, C.A.Th. Takkenberg and D. Crookall, eds. Simulation-gaming: On the improvement of competence in dealing with complexity, uncertainty and value conflicts. Great Britain: Pergamon.

Lane, D.C. 1995. On a resurgence of management simulations and games. The Journal of the Operational Research Society, 46, p. 604-625.

Leigh, E. 2004. Making learning a game. Public Management Electronic Journal, [online]. Available at http://e-journal.spa.msu.ru/images/File/2004/leigh.pdf [Accessed 2 February 2009].

Le Roux, I. and Steyn, B. 2007. Experiential learning and critical reflection as a tool for transfer of business knowledge: An empirical case study of a start-up simulation intervention for nascent entrepreneurs. South African Journal of Economic and Management Sciences, 10 (3), p. 330-347.

Montouri, L.A. 2000. Organizational longevity: Integrating systems thinking, learning and conceptual complexity. Journal of Organizational Change Management, 13 (1), p. 6173.

Senge, P.M. 1994. The fifth discipline: The art E' practice of the learning organisation. New York: Currency.

Styhre, A. 2002. Non-linear change in organizations: Organization change management informed by complexity theory. Leadership E Organization Development, 23 (6), p. 343-351.

Thiagarajan, S. 2003. Design your own games and activities: Thiagi's templates for performance improvement. San Francisco: John Wiley \& Sons.

Townsley, P. 2010. Review of coastal and marine livelihoods and food security in the Bay of Bengal Large Marine Ecosystem Region. UK: The Innovation Centre, University of Exeter.

Van Tonder, C.L. 2004. Organisational change: Theory and practice. Pretoria: Van Schaik.

Wilson, J.A. 2006. Matching social and ecological systems in complex ocean fisheries. Ecology and Society, 11 (1), p. 9. Available at http://www.ecologyandsociety.org/ vol11/iss1/art9[Accessed 21 April 2009]. 